\title{
Tri-National de la Sangha Landscape
}

Maurice Tadjuidje, Barthelemy Dipapoundji and Saturnin Brice Mowawa

\section{Background}

The Tri-National de la Sangha (TNS) landscape came into being during a summit of heads of state and Governments of the Economic Community of Central African States held on 17 March 1999 in Yaoundé, Cameroon. This summit led to:

- Signing of the Yaoundé Declaration by Central African heads of state for the collaborative management of forest ecosystems;

- Foundation of the 'Conference of Ministers in charge of Central African Forests', which later became COMIFAC (Central African Forests Commission) following the adoption of its convergence plan in 2005;

- Signature in December 2000 of the cooperation agreement to establish the TNS, between the governments of the Republic of Cameroon, Congo and the Central African Republic (CAR);

- Adoption of the convergence plan in February 2005;

- Establishment of a trust fund for Tri National de la Sangha (FTNS);

- Commitment of the African Development Bank to support COMIFAC in the implementation of the convergence plan through the establishment the Congo Basin Ecosystems Conservation Support Program (PACEBCO);

- Adoption of the PACEBCo approach through the Programme Management Unit based in Yaoundé, with satellites in the six ecological landscapes which form the TNS.

\section{Geographic location}

The TNS is made up of three contiguous national parks - Nouabalé-Ndoki (Congo), Lobeke (Cameroon) and Dzanga-Sangha (CAR) - and their surroundings. The landscape covers an area of $44000 \mathrm{~km}^{2}$ (see Figure 1). The climate is generally humid with an average recorded rainfall between 1500 and $2000 \mathrm{~mm}$ from April to December, and a short dry season from January to March.

\section{Institutional and legal context}

The TNS is a transborder conservation area for the shared management of contiguous protected areas, which fall under the territorial jurisdiction of the three separate states concerned. The contracting parties have committed to develop common management objectives and regulations in line with the cooperation agreement signed on 7 December 2000. This led to the establishment of the following bodies:

- Tri-National Committee of Supervision and Conflict Resolution
- Tri-National Scientific Committee

- Tri-National Monitoring Committee

- Tri-National Committee for Planning and Execution, the source body for all TNS activities.

\section{Population}

The total population in the TNS is 191,000 inhabitants, who are relatively unevenly distributed across the TNS, with an urbanisation rate considerably higher than the national average (in industrial towns and villages). Administrative centres are situated exactly at the periphery of the TNS. The economic activities of the communities are essentially a function of their needs in terms of food, bush meat and non-timber forest products (NTFP). In this context, revenue originates mostly from the harvesting of forest products and the use of animal resources. These centres are an important TNS component for land use planning.

\section{Land allocation and use in the TNS}

The land use plan was approved by each TNS state and then by the whole TNS in November 2009 in Yaoundé (Cameroon). Land allocation and use concern:

- National parks

- Forest concessions

- Hunting management units (hunting as a recreation and community management activity)

- Farming areas

- Fishing areas

- Mining areas

\section{Social and economic features}

The TNS economy is based entirely on developing natural resources:

- Timber harvesting

- Development of tourism

- Craft industries

- Wildlife-based activities (bush-meat and safaris)

- Palm wine production

- Raphia production

- Fishing industry

- Harvesting of other NTFP (gnetum, mushrooms, caterpillars etc.)

- Farming

\section{Tenure and resource rights of the people}

Land tenure in the TNS is governed by statutory and customary law. In the TNS, in addition to the sovereignty of 

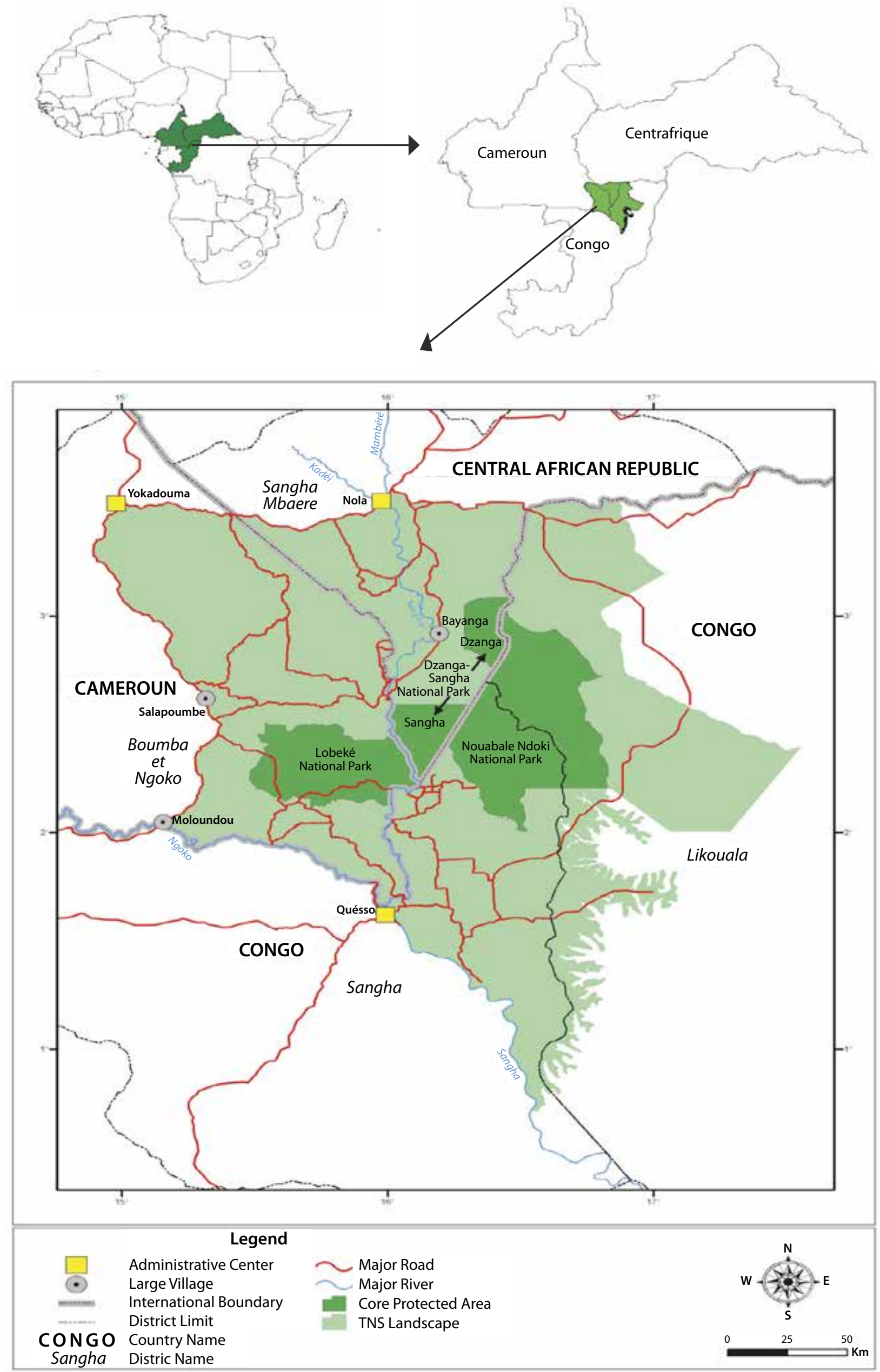

Figure 1. The Tri-National de la Sangha Landscape in the Congo Basin

Source: Zacharie NZOOH DONGMO/Project Manager Lobeke - WWF Central African Regional Programme Office (CARPO) 
each state which prevails over permanent public forest land, there are specific customary estates where forest rights are granted.

\section{Deforestation}

Deforestation in the landscape stems from human activities relating to slash-and-burn agriculture and mining (for gold and diamonds), as well as timber logging. The impacts of the latter are now controlled due to the development of management tools and forests product certification schemes. Deforestation is more commonly observed around inhabited areas, along rivers (mainly for mining) and cultivated areas along roads. A report from the Livelihoods and Landscapes Strategy Programme of the International Union for the Conservation of Nature (March 2008) shows that deforestation rates in Cameroon and the Central African Republic are stable, varying between 0 and 1 percent. The Food and Agriculture Organisation (FAO) estimates deforestation rates in Cameroon at 0.6 percent, while rates in Congo vary between 0.1 and 0.15 percent, and rates in the Central African Republic are below 1 percent, due to an end to logging in the Tri-National de la Sangha.

\section{Biodiversity}

The forest landscape in the TNS includes a large portion of low Guineo-Congolese forest, which is richly populated with African mahogany and great mammals. The three parks mentioned in the introduction constitute the main protection areas in the TNS.

More than 95 percent of the landscape is covered by forest, which ranges from semi-deciduous in the northwest to swampy in the southeast, with many natural glades inside and outside protected areas and Forest Management Units (FMUs). The landscape is home to major populations of some of the most threatened animal species on the continent. Great mammals such as forest elephants, great primates (lowland gorillas, chimpanzees), antelopes (bongo, sitatung), small mammals (colobi, Cercopithecus etc.), carnivores (leopards, golden cats, mongoose) and rodents. Wild birds are also abundant with several resident and migratory bird species. The TNS is unusual in that it is irrigated from North to South by the Sangha River, the main river in the region which has a varied and partly undiscovered piscifauna, with many fish families such as Lates Niloticus known as Nile perch, Malapterudae (electric fish), Mormyridae (Kpété) etc.

Apart from the protected areas, the landscape is dominated by forest concessions that have expanded exponentially during the past two decades through commercial timber logging in the region.

\section{Institutional partners}

Various actors are involved in the management of resources in the TNS. They are:
- civil society represented by national Non-Governmental Organisations and associations,

- $\quad$ financial partners: PACEBCo (Congo Basin Ecosystems Conservation Support Program), KfW (German Development Bank)/GIZ (German International Cooperation Agency), CAWHFI (Central African World Heritage Forest Initiative), FTNS (Tri-National de la Sangha Foundation) and the EU (European Union),

- national government bodies in charge of forests, fauna, protected areas and tourism,

- $\quad$ international non-governmental organisations fighting for conservation: World Wildlife Fund for Nature, International Union for Conservation of Nature (IUCN), Wildlife Conservation Society (WCS), etc.,

- $\quad$ private sector: forestry and mining companies and safari operators,

- $\quad$ communities with different population groups.

\section{Threats on resources}

Uncontrolled exploitation of resources in the TNS stems from human impacts on biodiversity. The pressure from poaching and illegal hunting remains the most severe threat, as well as uncontrolled extraction of gold and diamonds, which is more devastating than timber logging. The destruction of forests by fire for slash-and-burn agriculture is also on the list of threats. The biological diversity of the TNS is constantly threatened by human encroachment in protected areas and this is a major cause of habitat and animal species decline and fragmentation.

\section{Opportunities for Adaptation and REDD}

The main opportunities for the Tri-National de la Sangha to adapt to climate change and successfully engage in the REDD process are:

- $\quad$ Financing by financial partners of community development activities (EU, PACEBCo etc.);

- Development of initiatives and associations on adaptation and mitigation to climate change;

- Development of actions for sustainable and good management (certification, management planning, enforcing laws on forestry the environment and wildlife) in national policies and approaches at various decisionmaking levels.

\section{Challenges and constraints}

The effects of climate change are a global challenge, and the TNS cannot be excluded since the wellbeing of the people is at stake. One of the greatest challenges is to reverse the forest degradation trend caused by high deforestation rates. With this as an objective, CIFOR has implemented various climate change adaptation projects in TNS areas - supporting farming communities and distributing improved varieties of short-cycle corn seeds. It is also important to identify and implement activities which mitigate climate change. 


\section{Images showing the rich biodiversity in the TNS}

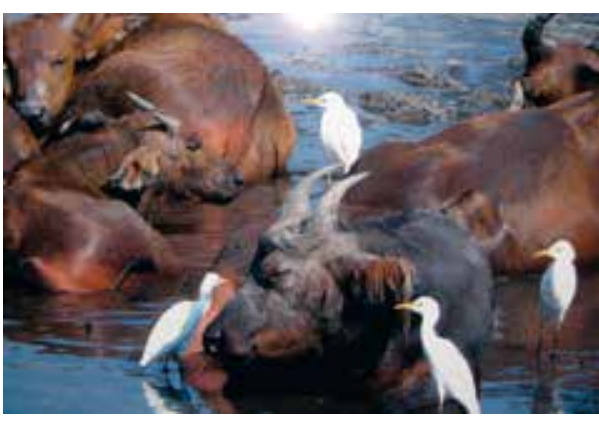

Forest buffalos and birds

(c) Thomas Breuer/Wildlife Conservation Society

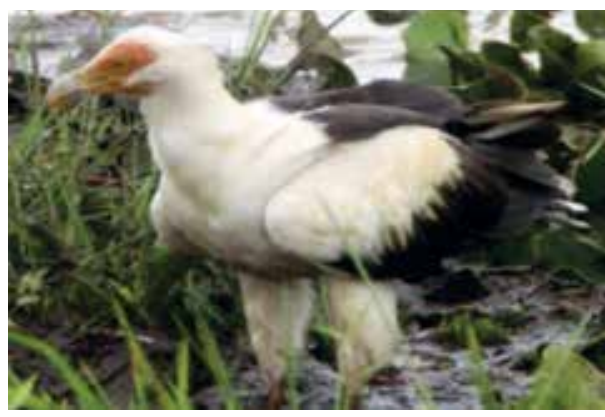

A bird of prey in a bay

(c) Thomas Breuer/Wildlife Conservation Society

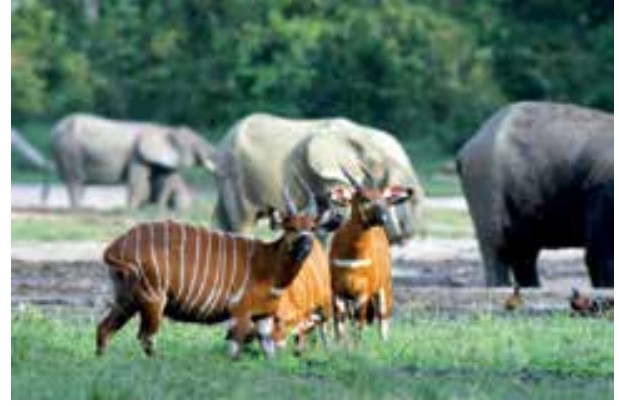

Bongo and elephants in Dzanga (c) Andrea Turkalo

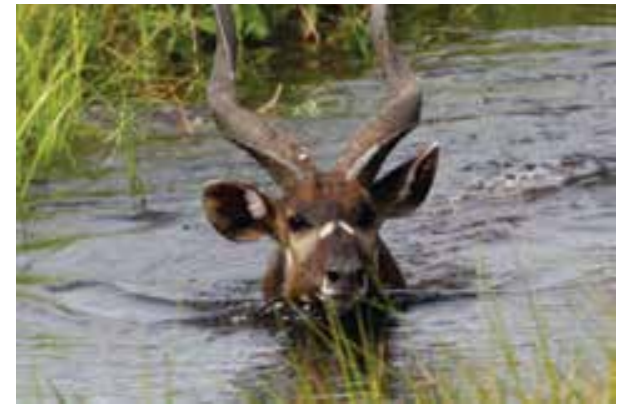

Sitatunga crossing a river

(c) Thomas Breuer/Wildlife Conservation Society

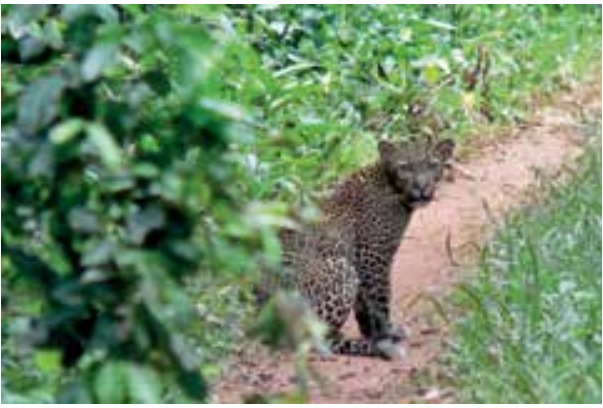

Panther in the Dzanga Sangha Protected Areas (c) Philipp Roth

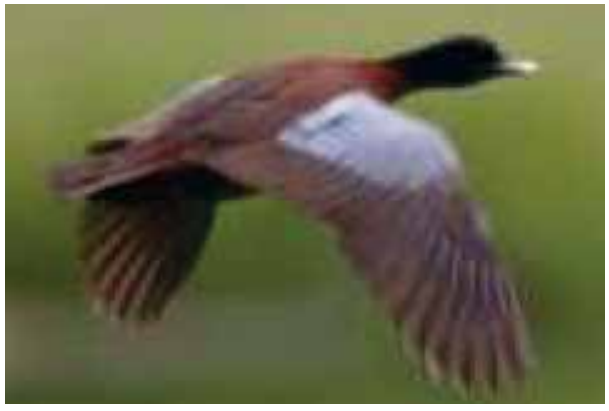

Flight of a water bird

(c) Thomas Breuer/Wildlife Conservation Society

COBAM is implemented by CIFOR under the African Development Bank (AfDB) grant to the Economic Community of Central African States (ECCAS) for financing the Congo Basin Ecosystems Conservation Support Program (PACEBCo).
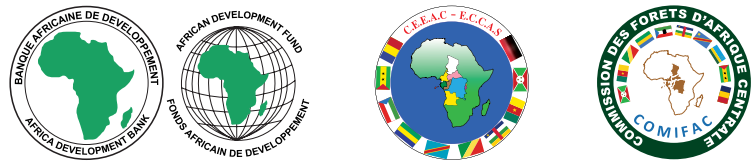

PACEBCo

cifor.org/cobam 